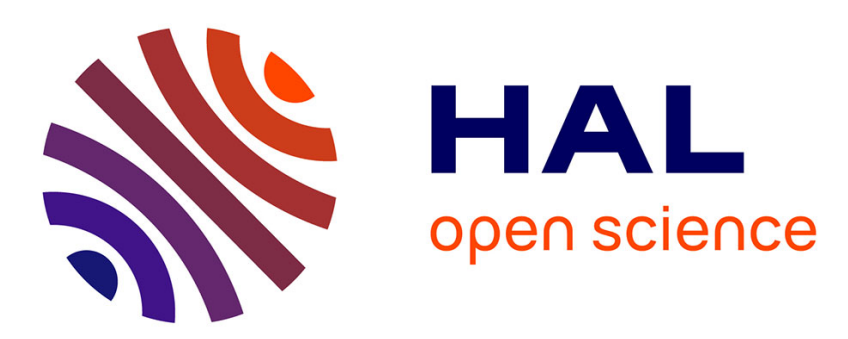

\title{
1. Étude du courant de transport par effet tunnel assisté thermiquement dans une jonction métal-semiconducteur
}

\author{
V.L. Rideout, C.R. Crowell
}

\section{To cite this version:}

V.L. Rideout, C.R. Crowell. 1. Étude du courant de transport par effet tunnel assisté thermiquement dans une jonction métal-semiconducteur. Revue de Physique Appliquée, 1970, 5 (6), pp.900-900. 10.1051/rphysap:0197000506090001 . jpa-00243471

HAL Id: jpa-00243471

https://hal.science/jpa-00243471

Submitted on 1 Jan 1970

HAL is a multi-disciplinary open access archive for the deposit and dissemination of scientific research documents, whether they are published or not. The documents may come from teaching and research institutions in France or abroad, or from public or private research centers.
L'archive ouverte pluridisciplinaire HAL, est destinée au dépôt et à la diffusion de documents scientifiques de niveau recherche, publiés ou non, émanant des établissements d'enseignement et de recherche français ou étrangers, des laboratoires publics ou privés. 


\title{
1. ÉTUDE DU COURANT DE TRANSPORT PAR EFFET TUNNEL ASSISTÉ THERMIQUEMENT DANS UNE JONCTION MÉTAL-SEMICONDUCTEUR
}

\author{
V. L. RIDEOUT et C. R. CROWELL \\ Univ. of Southern Calif.
}

Nous présentons ici une étude expérimentale du courant de transport par l'émission de champ thermoionique dans une barrière de Schottky. Nous avons réalisé des mesures de caractéristiques couranttension $(I-V)$, capacité-tension $(C-V)$ et les mesures de seuil photo-électrique pour des températures $\mathrm{T}=13-300^{\circ} \mathrm{K}$ sur des contacts de $\mathrm{Pt}$ et de siliciure de $P$ t avec du silicium de type $n$ d'un dopage de $210^{15}$ à $210^{18}$ impuretés $/ \mathrm{cm}^{3}$. Les mesures $I-V$ sont comparées avec les résultats théoriques de l'émission de champ thermoionique pour le courant de transport. Les barrières de siliciures de $\mathrm{Pt}$ ont été obtenues par recuit des contacts de $\mathrm{Pt}$ à $370^{\circ} \mathrm{C}$. Le courant de fuite en polarisation positive et négative et les valeurs de $n\left(\frac{1}{n}=k T \frac{\partial 1 n I}{\partial V}\right)$ ont été observés après recuit. Les diodes de siliciure présentent un anneau périphérique distinct, la structure physique et la composition chimique est différente du siliciure central et du silicium. 